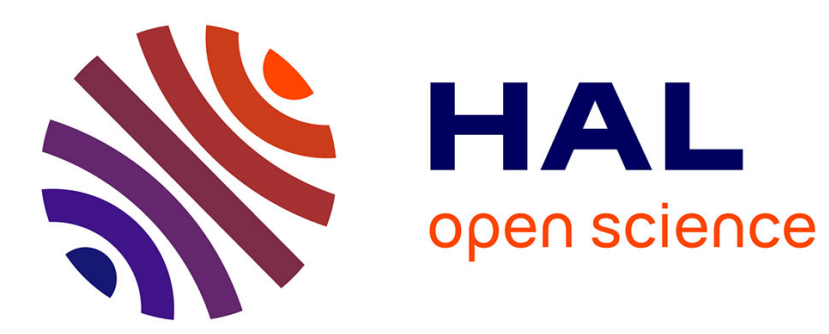

\title{
3D FEM simulations of shoulder milling operations on a 304L stainless steel
}

Aurelien Maurel-Pantel, Michael Fontaine, Sébastien Thibaud, Jean-Claude Gelin

\section{- To cite this version:}

Aurelien Maurel-Pantel, Michael Fontaine, Sébastien Thibaud, Jean-Claude Gelin. 3D FEM simulations of shoulder milling operations on a 304L stainless steel. Simulation Modelling Practice and Theory, 2012, 22, pp.13-27. 10.1016/j.simpat.2011.10.009 . hal-00679945

\section{HAL Id: hal-00679945 \\ https://hal.science/hal-00679945}

Submitted on 16 Mar 2012

HAL is a multi-disciplinary open access archive for the deposit and dissemination of scientific research documents, whether they are published or not. The documents may come from teaching and research institutions in France or abroad, or from public or private research centers.
L'archive ouverte pluridisciplinaire HAL, est destinée au dépôt et à la diffusion de documents scientifiques de niveau recherche, publiés ou non, émanant des établissements d'enseignement et de recherche français ou étrangers, des laboratoires publics ou privés. 


\title{
3D FEM simulations of shoulder milling operations on a 304L stainless steel
}

\author{
A. Maurel-Pantel ${ }^{* 1}$, M. Fontaine ${ }^{2}$, S. Thibaud ${ }^{2}$, J.C. Gelin ${ }^{2}$ \\ ${ }^{1}$ LMA, Aix-Marseille Univ, CNRS, UPR 7051, Centrale Marseille, F-13402 Marseille Cedex 20, France. \\ ${ }^{2}$ FEMTO-ST Institute, Department of Applied Mechanics, UMR CNRS 6174, ENSMM/ Franche-Comté University, \\ Besançon, France. \\ *Corresponding author: Dr. Aurélien MAUREL-PANTEL \\ Address: Laboratoire de Mecanique et d'Acoustique, 31 chemin J. Aiguier, 13402 Marseille \\ cedex 20, France \\ Tel: + $33(0) 491164227$ \\ Fax: + $33(0) 491164481$ \\ Email: maurel@lma.cnrs-mrs.fr
}




\begin{abstract}
This paper describes investigations realized to perform simulations of shoulder milling operations on AISI 304L stainless steel using the commercial software LS-Dyna $^{\odot}$. A Lagrangian formulation with an explicit solution scheme and a penalty contact algorithm has been used. Many experiments were performed in shoulder milling configurations in order to study the machinability of this material and also to validate results obtained from the developed 3D finite elements model. In the simulations, the material behaviour is modelled with a classical Johnson-Cook law. Some enhancements and simplifications had to be made in geometry, meshing, friction and temperature considerations for limiting the calculation time. The final aim consists to obtain realistic numerical cutting forces for shoulder milling operations.
\end{abstract}

Keywords: Milling, Cutting forces, Finite element method, 304L stainless steel 


\section{Nomenclature}
$\rho \quad$ Density
c Calorific capacity
$\boldsymbol{T}$ Temperature
$\boldsymbol{\beta}$ Taylor-Quinney coefficient
$\bar{\sigma} \quad$ Equivalent stress
$\dot{\bar{\varepsilon}} \quad$ Equivalent strain rate
A Yield stress constant of Johnson-Cook law
B Strain hardening constant of Johnson-Cook law
n Strain hardening exponent of Johnson-Cook law
C Strain rate hardening constant of Johnson-Cook law
$\boldsymbol{m}$ Temperature dependant coefficient of Johnson-Cook law
$\bar{\varepsilon}^{p} \quad$ Cumulated plastic strain
$\overline{\boldsymbol{\varepsilon}}_{\infty} \quad$ Plastic strain limit before failure
$\mu_{s} \quad$ Static friction coefficient
$f \quad$ Feed rate
$N \quad$ Spindle frequency
$V_{C} \quad$ Cutting speed
$f_{t} \quad$ Feed per tooth
$\boldsymbol{d}_{\boldsymbol{a}} \quad$ Axial depth of cut
$\boldsymbol{d}_{\boldsymbol{r}} \quad$ Radial depth of cut
$\boldsymbol{r}_{\varepsilon} \quad$ Radius of the tool cutting edges
$\boldsymbol{a}_{\text {elem }}$ Meshsize of the machined part of the material
$\tau \quad$ Number of elements in the chip maximal section
$\boldsymbol{\theta}$ Angular position of the mill
$\boldsymbol{F}_{\boldsymbol{X}} \quad$ Cutting force orthogonal to the feed
$\boldsymbol{F}_{\boldsymbol{Y}} \quad$ Cutting force along the feed axis (Feed force)
$\boldsymbol{F}_{Z} \quad$ Cutting force along the tool axis (Axial force) 


\section{Introduction}

During the last thirty years, many numerical models using finite elements method have been developped for material forming simulations. Industries and research laboratories have focused on these developments to try to understand, analyse and quantify the physical phenomena in the metal cutting process. In the field of machining, these models are complementary to the analytical models, more efficient for considering industrial operations but limited in output data. The FE models are used particularly to provide more information on strain, stress contours and temperature field in the machined material zones or in the tool. But up by now, numerical models have essentially described elementary cutting configurations (orthogonal or oblique) and complex processes as milling or drilling are not widely considered. Numerical models are essentially based on three possible descriptions: lagrangian, eulerian and arbitrary lagrangian eulerian (ALE). New approaches based on particle methods or meshless methods have been developed but they are not widely used in the machining field. In machining operations, the optimisation methodology requires to select appropriate tool, tool pathes and cutting conditions (especially cutting speed and feed). The modelling developments are then conducted to study the influence of process parameters on process efficiency in terms of quality, productivity and cost reduction. For example, (Lo, 2000) [1] study the influence of the cutting rake angle in a copper alloy and (Yen et al., 2004) [2] the effect of tool edge radius. The final goal of these approaches is to establish a reliable methodology to optimise the process. Moreover, all cutting processes have a similarity: the chip formation. The generation mode has been studied for a long time to describe formation, segmentation and flow mechanisms of the chip. In this field, the models must take into account severe contact conditions and large plastic strains. Numerical models of orthogonal cutting have been proposed in literature since the beginning of 90's and some works showed realistic results (Mamalis et al., 2001) [3], (Bäker, 2004) [4]. Many works have been carried 
out on different aspects linked to the machining field, as thermal phenomena, wear prediction, tool dynamics, residual stresses and the influence of material constitutive laws on results (Umbrello et al., 2007) [5,6] (Outeiro et al., 2007) [7]. Nevertheless, a very few papers and communications deal with the subject of numerical modelling of milling process. Only the thermomechanical analytical models relate full results on cutting forces close to the real machining conditions (Fontaine et al., 2006) [8]. The first works using finite elements method in milling have been carried out by (Ozel \& Altan, 2000) [9] using Deform-2D® software. The authors designed a 2D numerical model of the end milling process associated to an orthogonal cutting model following a circular path. The operation reproduces a slotting operation in P-20 steel with a cutting speed of $200 \mathrm{~m} \cdot \mathrm{min}^{-1}$ and a feed rate of $0.1 \mathrm{~mm} \cdot \mathrm{teeth}^{-1}$. The tool is a mill with one indexable insert presenting two opposite cutting edges and a diameter of $15.88 \mathrm{~mm}$. Comparisons are performed between numerical and experimental cutting forces. A correct agreement is obtained on the three axes of measurements by splitting chip flow calculation in the $\mathrm{XY}$ plane and along $\mathrm{Z}$ axis (tool axis). But the used assumptions of a chip formation contained in a plane is valid only for a particular tool with very small rake and helix angles. To conclude, the authors propose to improve the model in using behaviour and friction laws adapted to the high strain rates reached in machining. With the same idea, (Uhlmann et al., 2007) [10] proposed to divide the machining path in milling and to perform for each step an oblique cutting simulation in order to rebuild the milling cutting forces evolution. But the results demonstrate that the method is not able to provide the cutting forces measured experimentally. Accurate results have been presented by (Denkena et al., 2007) [11]. The authors developed a 3D simulation of high performance milling for aeronautic industries. This simulation was performed with Deform3D ${ }^{\odot}$ software. The model is based on a shoulder milling operation in aluminium with a cutting speed of $1250 \mathrm{~m} \cdot \mathrm{min}^{-1}$ and a feed rate of 0.3 mm.teeth $^{-1}$. The tool is a mill with indexable inserts and a diameter equal to 20 
mm. Accurate results are available on residual stresses and temperatures in the machined workpiece, but unfortunately no information is given about cutting forces evolution. In the present paper, a study of shoulder milling on an AISI 304L stainless steel is conducted. This steel is intensively used in chemical, biomedical and power plant industries. The 304L grade represents today $80 \%$ of the world-wide market of stainless steels. It is widely used in industriy for its very good forming capacity, an excellent resistance to corrosion and a high ductility. The aim is here to propose a new way to improve milling operations from predictive modelling and a new tool to verify physical issues. Moreover, a reliable model could replace many experimental tests usually needed each time a tool or a workpiece material is changed. In this study, AISI 304L austenitic stainless steel was used to help the manufacturers in the understanting of machining processes (Korkut et al., 2004)[12] (Tekiner \& Yesilyurt, 2004)[13] (O’Sullivan \& Cotterell, 2002)[14].

The developments related in this paper concern a finite element model of shoulder milling operations with an helical end mill. In milling, the cutting forces are usually the first criterion used for operations optimisation because of their utility in studying machinability, cutting stability and process monitoring. Therefore, a FE numerical modelling of milling is proposed in order to obtain numerical cutting forces. The numerical results are finally compared to cutting forces calculated by analytical method and to experimental cutting forces measured directly during the process.

\section{Design of numerical model}

To define properly this model, we have to determine the framework used and, in particular, the numerical simulation method adapted to obtain cutting forces in milling. Even if the arbitrary Lagrangian-Eulerian description seems to be the most appropriate method to model the investigated phenomena (high strain gradients, localisation phenomena, mesh separations, 
chip geometry and flow), this method is not retained here. Indeed, to get an efficient correlation between simulations and experiments, it is necessary to have an accurate prediction of material behaviour and a good evaluation of contact forces at the interfaces. That's why we have chosen a lagrangian description in this work. Nevertheless the lagrangian method presents some difficulties for the modelling of machining operations:

- The significative influence of the initial mesh and the necessity to use a remeshing method,

- Ability to automatically recognise possible localisation of strains field,

- The need to take into account fracture spread and mesh separation.

\subsection{Modelling assumptions}

In this section, the set of assumptions and the methods used in numerical simulations are defined. Firstly, we used a transient explicit dynamics algorithm (middled finite differences).This choice is motivated by the following reasons:

- The investigated phenomena are clearly related to a quick dynamical process in term of characteristic times (a tool revolution in 3ms) and in term of loading evolutions (high strain rates, loads suddendly changing during the machining operation).

- In spite of the conditional stability of the explicit time integration scheme, the set up of robust simulations is easier than with implicit time integration scheme.

- An explicit scheme is quite useful in the case of high non linearities associated to material behaviour, contact interface, friction law and high mesh distorsion.

Secondly, we consider a weak thermal-mechanical coupling in this study. In machining process, thermal phenomena (heating, friction at the interfaces) have a real influence on the material behaviour during cutting. But the lack of knowledge on phenomena at contact interfaces and coupling mechanisms imposes to use this hypothesis in first approximation. So 
in the developed simulations, the temperature evolution is only obtained by considering the dissipation due to mechanical process (heat dissipation). Moreover, the thermal transfer with the ambiant air is not considered (adiabatical hypothesis). Finally, the heat equation takes the following form:

$$
\rho c \frac{d T}{d t}=\beta \bar{\sigma} \dot{\bar{\varepsilon}}
$$

where $\beta$ is the Taylor-Quinney coefficient corresponding to heat fraction dissipated by deformation process, $\bar{\sigma}$ is the equivalent stress and $\dot{\bar{\varepsilon}}$ the equivalent strain rate.

Then, a three-dimensionnal modelling has been investigated in these simulations of milling. So we have to choose in this case solid elements adapted to the machining case modelled. The use of under-integrated solid elements with eight nodes (hexahedrons) and one integration point has been retained. The under-integration of these elements permits to decrease the calculation time and offers a high numerical robustness. But this element exhibits hourglass modes and a control of theses modes with an adapted method is necessary. In machining processes as turning and milling, the physical phenomena occuring at the tool/workpiece interfaces have to be modelled. To take into account these interface effects, we used a penalty contact algorithm. In these numerical models, rigid domain (the tool) and deformable domain (the machined part) are meshed with the same mesh density in order to provide a good stability of the contact algorithm. Classically, rigid elements are considered with an unsignificant influence on simulation. Nevertheless, in the case of contact simulations, the influence of the meshsize of rigid and deformable parts is quite important. If the rigid bodies are meshed with a greater size than deformable parts, the penalty algorithm can be unstable. In this case, a rigid element tries to balance a set of deformable elements in contact inside the influence zone. So mesh penetration problems quickly appear. To avoid this phenomenon in penalty algorithm, an identical mesh size is used for rigid and deformable 
parts. One disavantage of this approach is associated to the definition of contact areas and to the calculation time increasing. Practically, the use of a bucket sort algorithm permits to decrease this research during the simulation. The bucket sort algorithm is based on two steps: initial research and local research. The first step consists in a global localisation of the contact area and for each areas, an independant box is associated. Due to the explicit algorithm, the displacements are small between two time steps and the contact interface zones don't vary so much. So the bucket sort method is used to limit the geometrical zone where it has to be verified the contact conditions between all the elements.

\subsection{Material and friction behaviours}

In machining simulations, we choose to model the behaviour of the AISI304L stainless steel with a classical Johnson-Cook constitutive law (Johnson \& Cook, 1983) [15]. The material coefficients have been identified from Hopkinson bar tests. We define an isotropic hardening with an evolution defined by the scalar variable $R$ given by the following equation:

$$
R=\left[A+B \varepsilon^{n}\right]\left[1+C \ln \left(\frac{\dot{\varepsilon}}{\dot{\varepsilon}_{0}}\right)\right]\left[1-\left(\frac{T-T_{0}}{T_{f}-T_{0}}\right)^{m}\right]
$$

The material parameters are related in Table 1.

\begin{tabular}{c|c|c|c|c|c|c|c}
\hline$A(M P a)$ & $B(M P a)$ & $n$ & $C$ & $m$ & $\dot{\varepsilon}_{0}\left(s^{-1}\right)$ & $T_{f}\left({ }^{\circ} K\right)$ & $T_{0}\left({ }^{\circ} K\right)$ \\
\hline 253.32 & 685.1 & 0.3128 & 0.097 & 2.044 & 1.0 & 1698 & 296 \\
\hline
\end{tabular}

Table .1. Material parameters associated to the Johnson-Cook law defined for the AISI304L steel.

A critical point of finite elements simulations of cutting processes is associated to the chip formation and separation. To handle this, a chip formation criterion is introduced and based on strain localisation, cracking and failure. The accurate modelling of these complex physical mechanisms is very difficult, so we choose in first approximation to introduce an element separation criterion related to a material limit. This criterion is based on two discrete values of 
a scalar parameter noticed $\lambda$. The element deletion is considered activated $(\lambda=1)$ or not activated $(\lambda=0)$. The criterion is based on the cumulated plastic strain $\bar{\varepsilon}^{P}$ and defined by:

$$
\lambda=\left\langle\frac{\bar{\varepsilon}^{P}-\bar{\varepsilon}_{\infty}}{\left|\bar{\varepsilon}^{P}-\bar{\varepsilon}_{\infty}\right|}\right\rangle \text { with }\langle X\rangle= \begin{cases}0 & \text { if } X \leq 0 \\ 1 & \text { if } X>0\end{cases}
$$

where $\bar{\varepsilon}_{\infty}$ is the plastic strain limit value and define the removal of material. The influence of this parameter is quite sensible on the chip formation and a value of $\bar{\varepsilon}_{\infty}$ equal to 0.8 is used for the milling simulation. The chip formation and segmentation are strongly bound up to the tool/workpiece interface. In order to introduce a more accurate modelling of these phenomena, it is necessary to introduce the contact between geometries (interfaces between both meshes) and to consider the dissipative process produced at the inferfaces due to friction. These phenomena are extremely complex and vary accordingly to the cutting conditions, the tool geometry and in particular the material behaviours of tool and workpiece. Nevertheless, usually in machining, these phenomena are approximated with a static Coulomb law (4).

$$
\mu=\mu_{s}=0.8
$$

where $\mu_{\mathrm{S}}$ represent the static friction coefficient. We deduce the coefficient from turning tests performed by (Moufki et al., 2004) [16].

\section{Shoulder milling simulations}

After the introduction of the different assumptions used to perform simulations, the shoulder milling numerical model is presented in two configurations as shown in Figure 1. The classical parameters defining the tool geometry and its engagement are sumed up in Figure 1. The aim consists in simulating the process in cutting conditions which are reachable experimentaly. Indeed, this work concerns the simulation of academic configurations far 
away from the classical industrial conditions, but the comparison with the experimental measurement can be validated.

\subsection{Cutting conditions}

Two shoulder milling operations corresponding to the two main different cutting configurations are suggested: in up cutting and down cutting. The experiments and their cutting conditions are presented in Table 2. We could consider the milling operations chosen as academic due to the important value of feed velocity $f$ used. These cutting conditions are reachable on a milling machine, but the tool is strongly loaded and its wear is very quick. The global geometry of the tested tool is related in Table 3.

\begin{tabular}{|c|c|c|c|c|}
\hline$V_{C}\left(m \cdot \min ^{-1}\right)$ & $f_{t}\left(m m\right.$. tooth $\left.^{-1}\right)$ & $d_{a}(m m)$ & $d_{r}(m m)$ & $r_{\varepsilon}(\mu m)$ \\
\hline 250 & 0.2 & 0.5 & 2 & 30 \\
\hline
\end{tabular}

Table.2. Cutting conditions used for the shoulder milling simulations

\begin{tabular}{c|c|c|c}
\hline \multirow{2}{*}{$\boldsymbol{D}(\mathbf{m m})$} & \multicolumn{3}{|c}{ Angle } \\
\cline { 2 - 4 } & Rake $\left(^{\circ}\right)$ & Relief $\left(^{\circ}\right)$ & Helix $\left(^{\circ}\right)$ \\
\hline $\mathbf{6}$ & 1 & 3 & 30 \\
\hline
\end{tabular}

Table.3. Characteristics of the tool used for the shoulder milling simulations and experiments
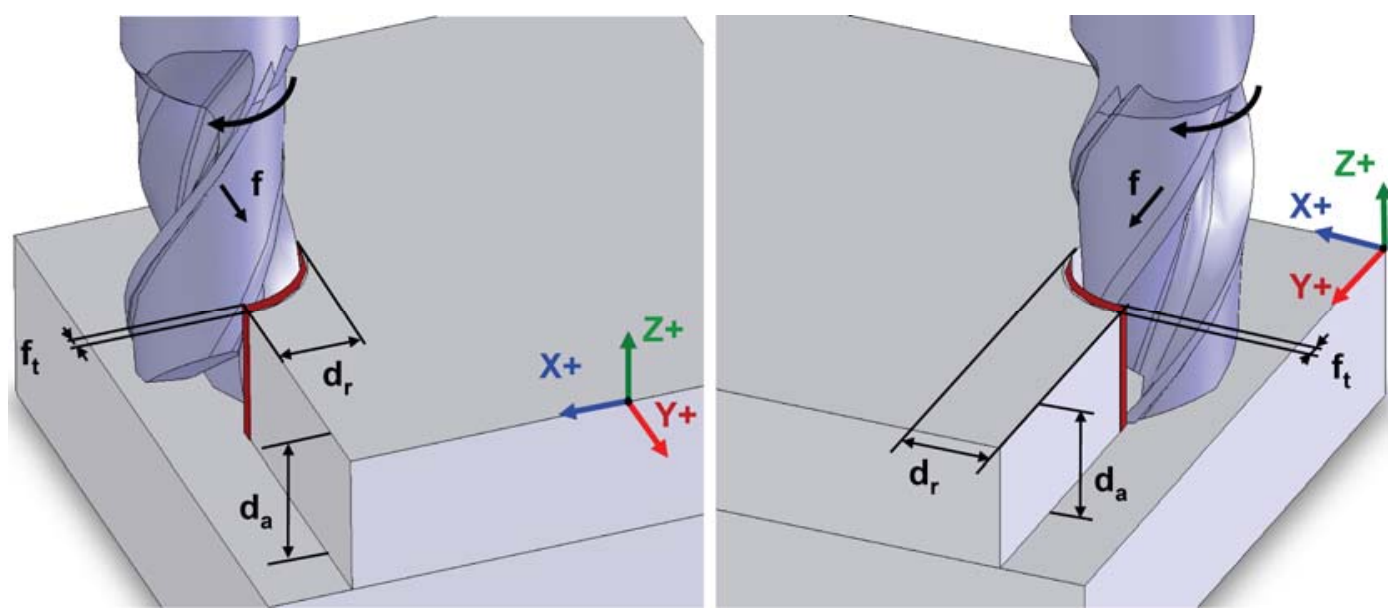

Fig.1. Geometrical parameters and tool engagement in up and down shoulder milling 


\subsection{Initial mesh and boundary conditions}

As seen in section 2.1, the workpiece mesh is a very important parameter of the numerical model. Indeed, a lagrangian description is used with a failure criterion, so the workpiece must be carefully meshed in order to obtain a representative chip formation and a satisfactory control of the contact algorithm between the tool and the machined material. Areas not directly sollicitated by the mill are designed with degressive mesh allowing an evacuation of stresses and an avoidance of undesirable numerical effects on stress values. But to perform a satisfying approach of chip formation, a minimal number of elements should be considered. If this condition is not respected, an incorrect chip formation is obtained and the curve shapes of cutting forces curves are far away from the rigid case. Different investigations led on the model have permitted to determine a condition based on the minimal size of elements $a_{\text {elem }}$ and the feed rate $f_{t}$ defined by :

$$
a_{\text {elem }}=\frac{f_{t}}{\tau} \quad \text { with } \quad \tau \geq 6
$$
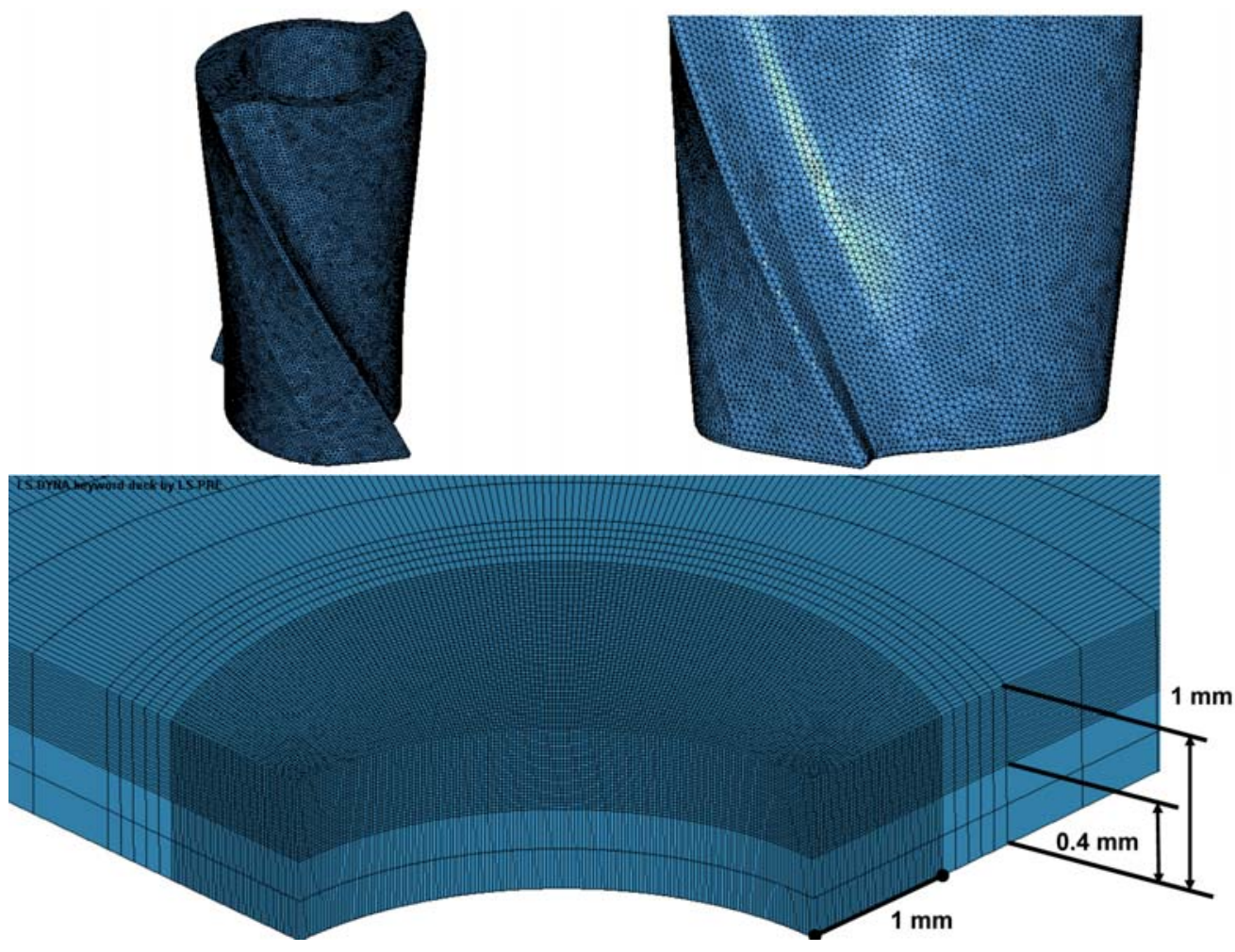

Fig.2. Mesh of the milling tool and workpiece 
where $\tau$ is a scalar parameter and, for these milling simulations of milling, the value of $\tau$ was chosen equal to 10 .

Moreover, in the model the feed per tooth is equal to $f_{t}=0.2 \mathrm{~mm}$, so in relation to the equation (5), the size mesh parameter $\boldsymbol{a}_{\text {elem }}$ is equal to $20 \mu \mathrm{m}$. Then the mesh, in tool axis direction, is defined for a depth corresponding to $0.6 \mathrm{~mm}$. The mesh related in figure 2 is made to allow four tooth pathes and is composed of 400,000 hexaedric elements.

In literature, some works underline the strong influence of the tool geometry on the chip formation in milling (Movahhedy et al., 2002) (Yen et al., 2004)[17][18]. In this context, we have to mesh with methodology and accuracy the mill geometry. For this, the real tool was digitalized with a 3D laser scanner and the obtained CAD model was meshed. Due to the complex geometry of the tools, a simplified model was used in calculation to reproduce accurately the helix and the rake angles only. For the control of contact, the perfect sharp edges are very harmful. So experimental measures of tool edge sharpness were conducted with an optical 3D measurement device Alicona InfiniteFocus ${ }^{\odot}$. The results show a $30 \mu \mathrm{m}$ radius for tool edge sharpness and this value was retained to reconstruct the cutting edge in the CAD model. The tool mesh used is related in Figure 2 and is composed of 300,000 tetraedric elements. The initial mesh with boundary and initial conditions are related in Figure 3. We introduced two different boundary conditions. The first one consists in limiting the tool motion to the translation in feed direction ( $\mathrm{Y}$ axis) and rotation ( $\mathrm{Z}$ axis). The second one consists to constrain the set of nodes localised at the workpiece basis in displacements and rotations. 


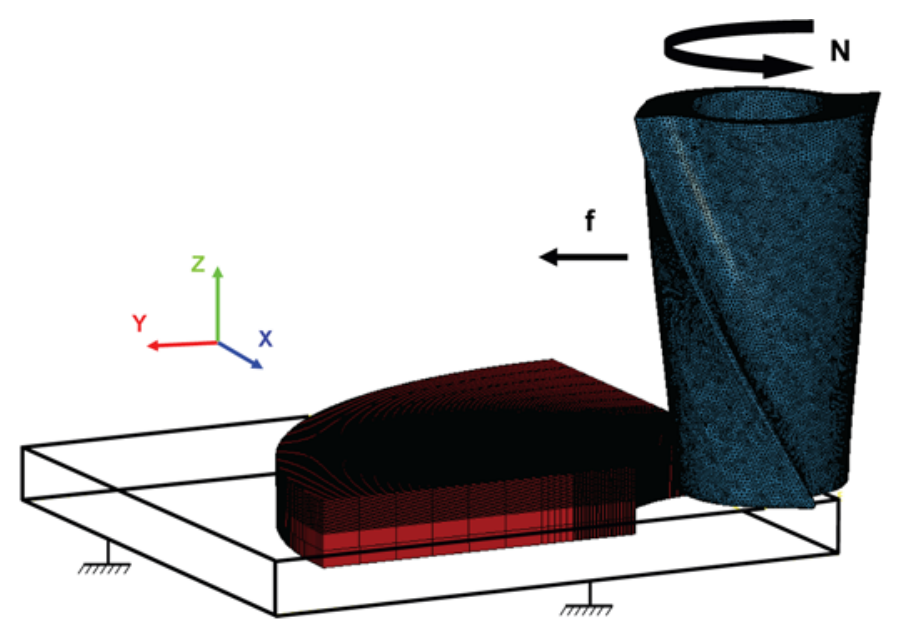

Fig.3. Initial meshes and boundary conditions

\subsection{Simulation results}

The LS-DYNA v970 software is used to perform simulations. In the case of a simulation associated to a four tooth pathes, the calculation time is about 20 days in SMP on a biprocessor 3,2 GHz with 4Go RAM. This computation time is about 6 days on a cluster equiped with 8 processors 3,2 GHz with 64Go RAM with a MMP version of LS-DYNA. The differents results obtained at the end of calculation are exposed in this section. In Figure 4 and Figure 5, different steps of the chip formation, respectively in up milling and down milling, are related for different angular positions of the mill described in Figure 6. 


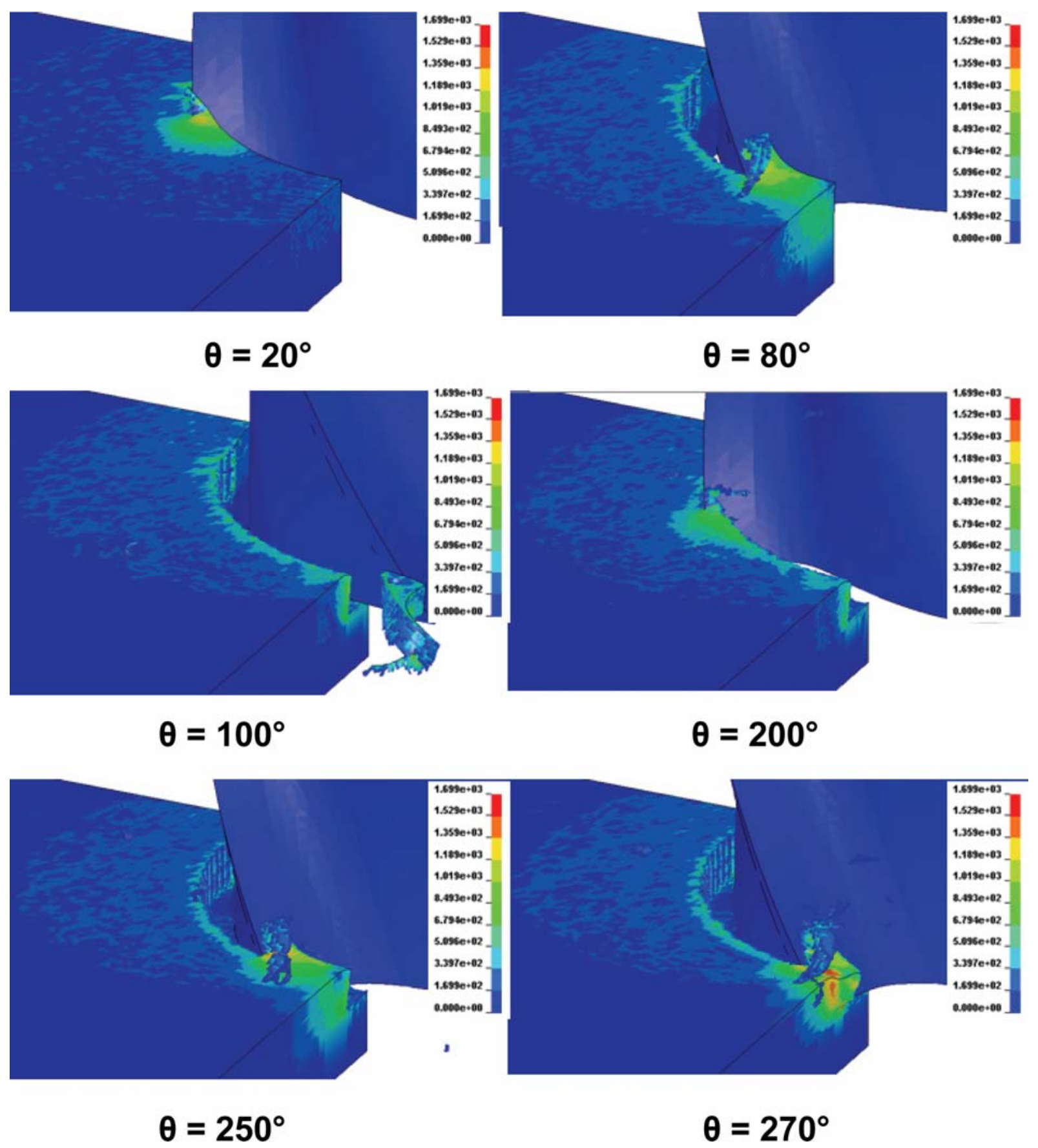

Fig.4. Von Mises stress contours in shoulder milling (up milling configuration, two tooth pathes) 

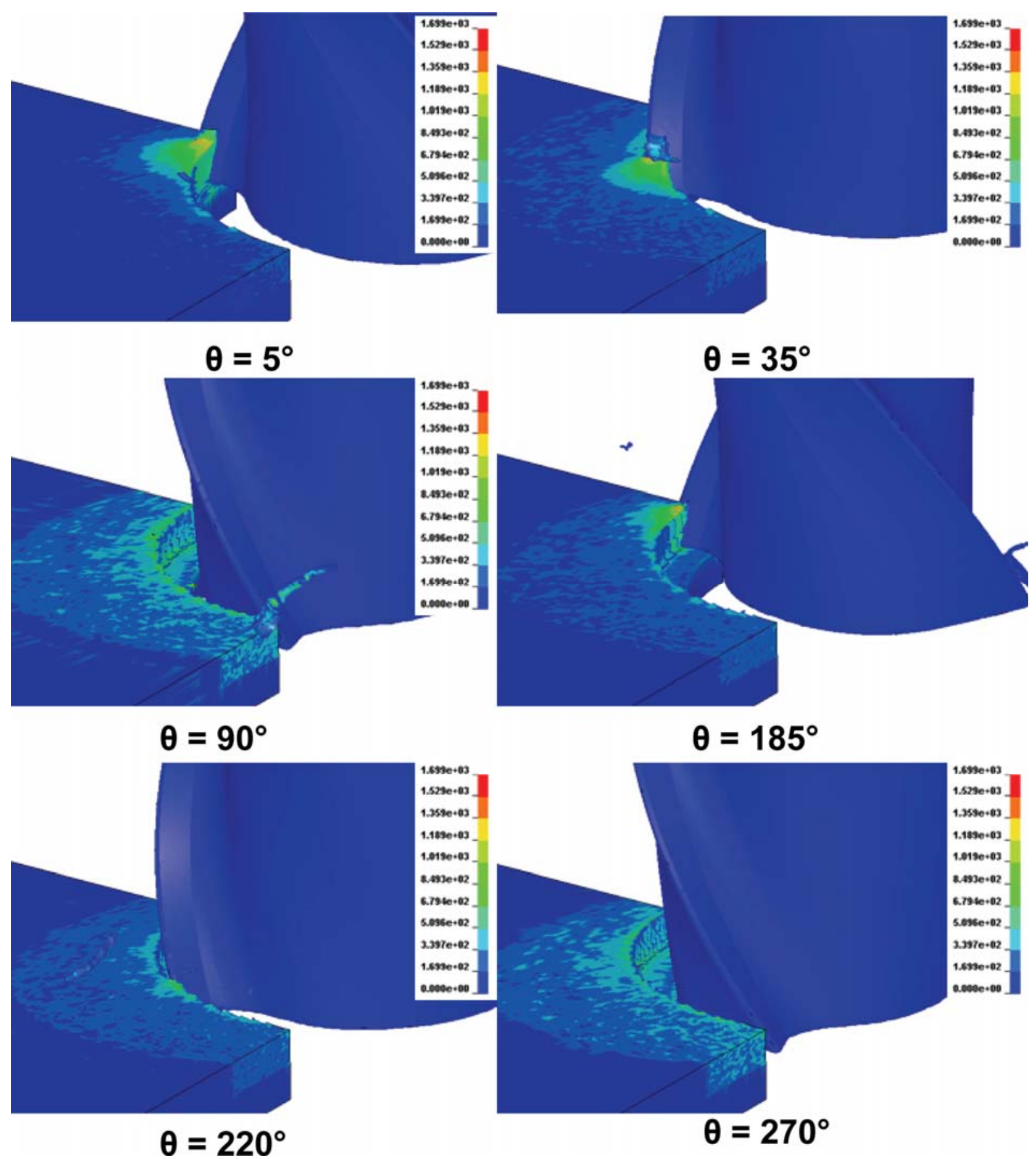

Fig.5. Von Mises stress contours in shoulder milling (down milling configuration, two tooth pathes)

The failure criterion and the introduced mesh permit to obtain a proper chip formation in milling. In up milling case, as related on Figure 7, the failure begins at the tool extremity, and then the chip leaves the machined surface but stays hung to the following rough surface. Finally, the tool finishes its motion in the material and the chip is splitted off completely and evacuated. 


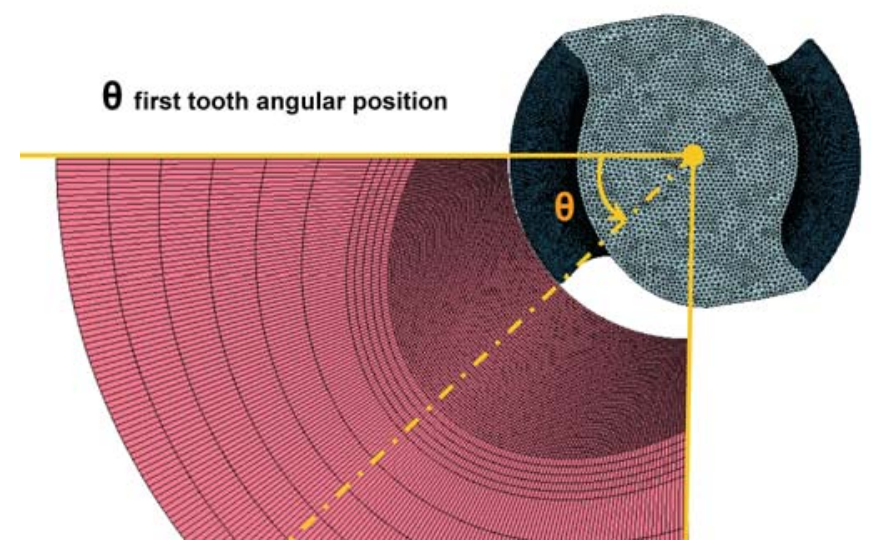

Fig.6. Definition of the angular position of the mill

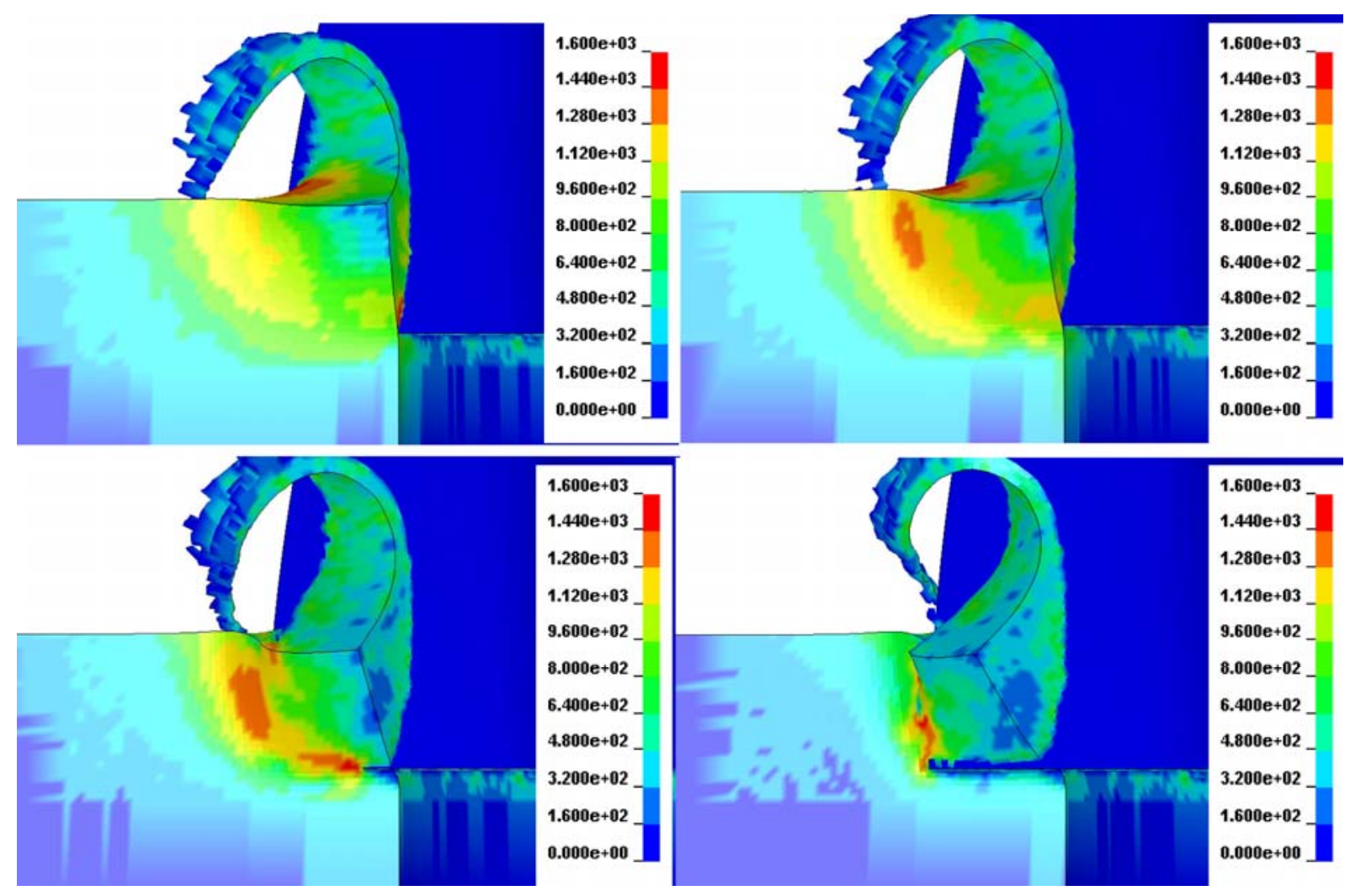

Fig.7. Von Mises stress contours during the chip separation

The energy balance provided by the software allows verifying that the total energy corresponds to the sum of the kinetic, internal and sliding energies as related in Figure 8. And also, it can be verified that the hourglass energy is negligible during the calculation. It is also 
important to mention that the internal energy increases under the effect of continuous failure of the chip elements. A constant value of the total energy corresponds to a configuration where no tooth is in contact with the workpiece. The kinetic energy also increases slightly under the effect of chip ejection: the chip goes away of the workpiece with a speed imposed by the mill.

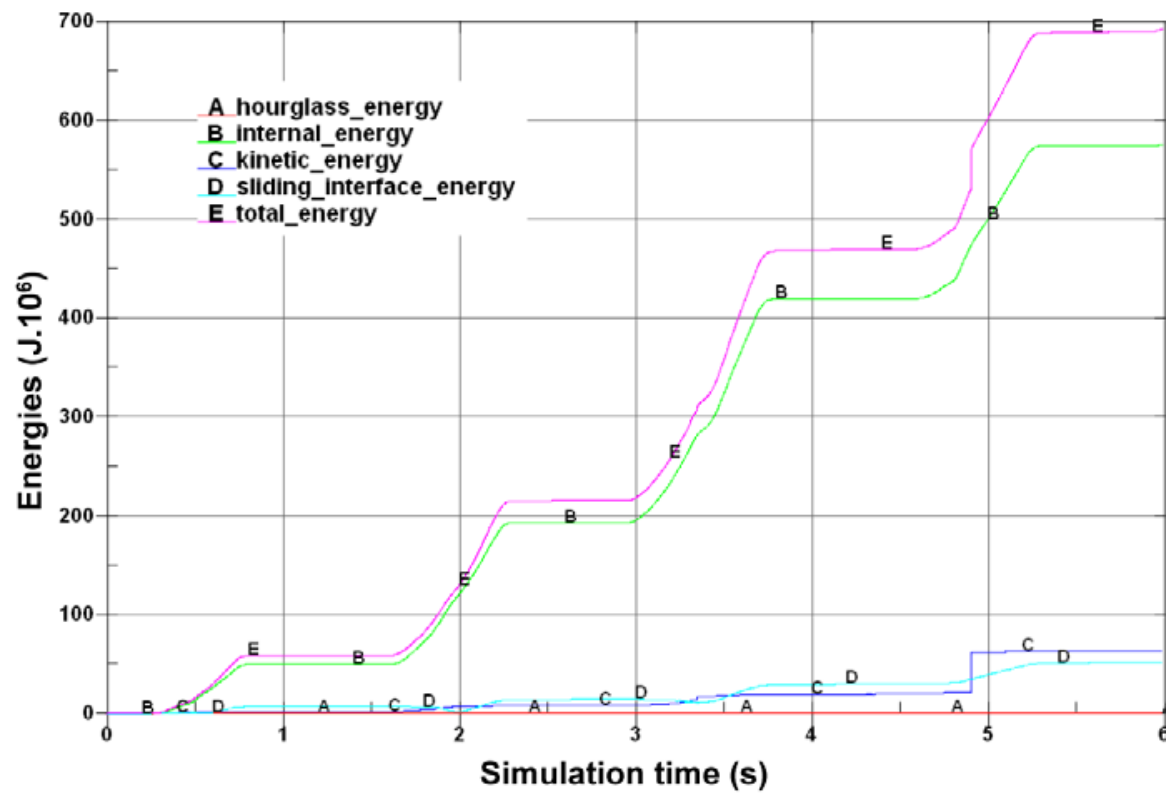

Fig.8. Energies curves related to different mechanisms (total, internal, kinetic, sliding and hourglass)

We remark also that at the beginning of the calculation, a harmful effect of the elements failure on the contact control gives a positive value for the contact energy. This effect is due to the fact that the separated chip remains always active in the tool/chip contact. The calculation shows proper variations concerning the energies. This first step being validated, it is assumed that the different observations concerning stresses, strains and cutting forces can be compared to experimental results. The cutting forces curves obtained at the end of the shoulder milling simulations in up and down milling configurations are related in Figure 9.

A procedure is used to filter the numerical and dynamical oscillations of the curves. Nevertheless, we observe numerical noise on curves mainly due to the sequential way of the 
elements failure. As seen before the models simulate four tooth pathes, the first path initialise the mill position in the model, so the first peak is not considered in this discussion.
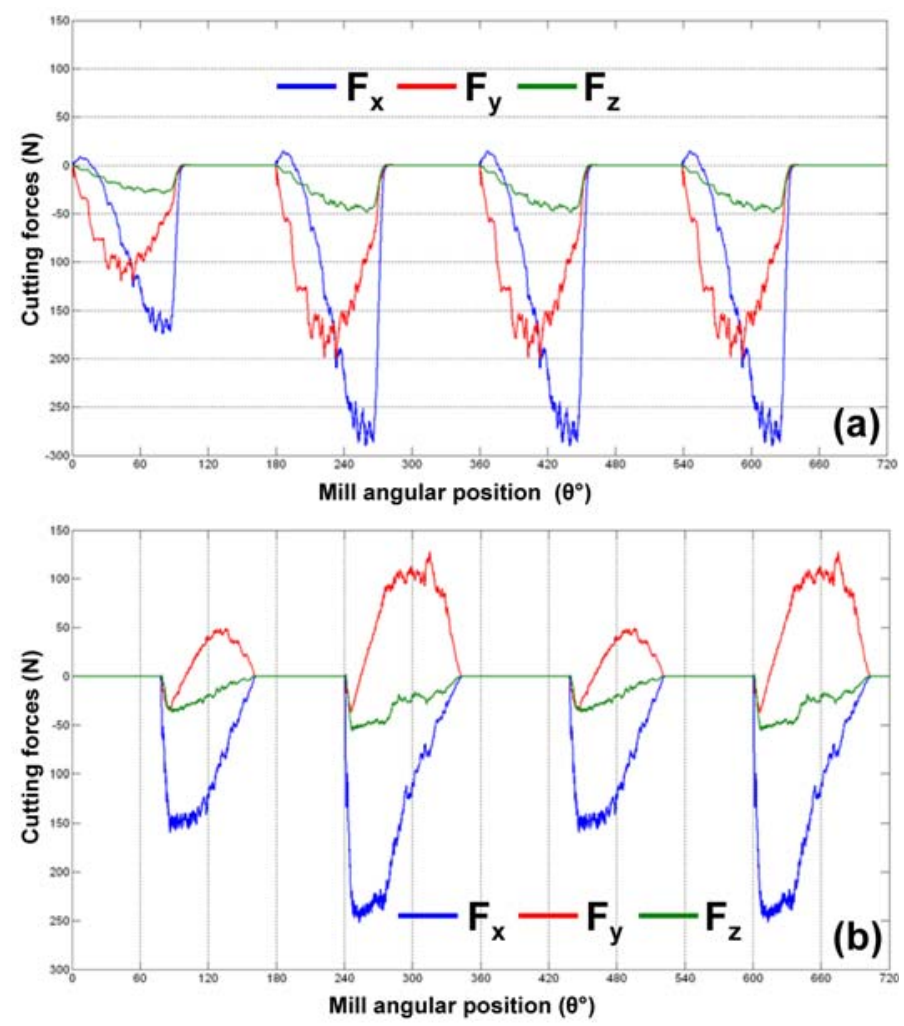

Fig.9. FEM cutting forces for four tooth pathes in up (a) and down (b) milling configurations

For the three last tooth pathes in up milling configurations, we can note a very good repeatability and a good similarity in the tool engagement on the cutting forces curves. In down milling, we observe a discrepancy on the third peak between the second and the last peaks. This phenomenon is mainly due to the second tooth path that cuts more than the maximal chip section defined by the feed rate. Indeed in down milling, the mill begins by taking a maximal chip section. The second tooth path pulls up a lot of elements and reduces the next chip section. This problem is due to the mesh imposed by lagrangian finite element model.

In order to validate the numerical model, a study of up milling numerical cutting forces was led to compare the simulated curves obtained with a validated analytical model developed by 
(Fontaine et al., 2006) [8][19] and the curves obtained experimentally in the same cutting conditions.

\subsection{Comparisons between finite elements model and analytical model}

The comparisons between the finite element model and analytical curves are related in Figure 10. This comparison is very important to validate the numerical modelling of milling. Therefore, we are able to compare the curve shapes of cutting forces curves between two numerical models based on a rigid tool engagement.
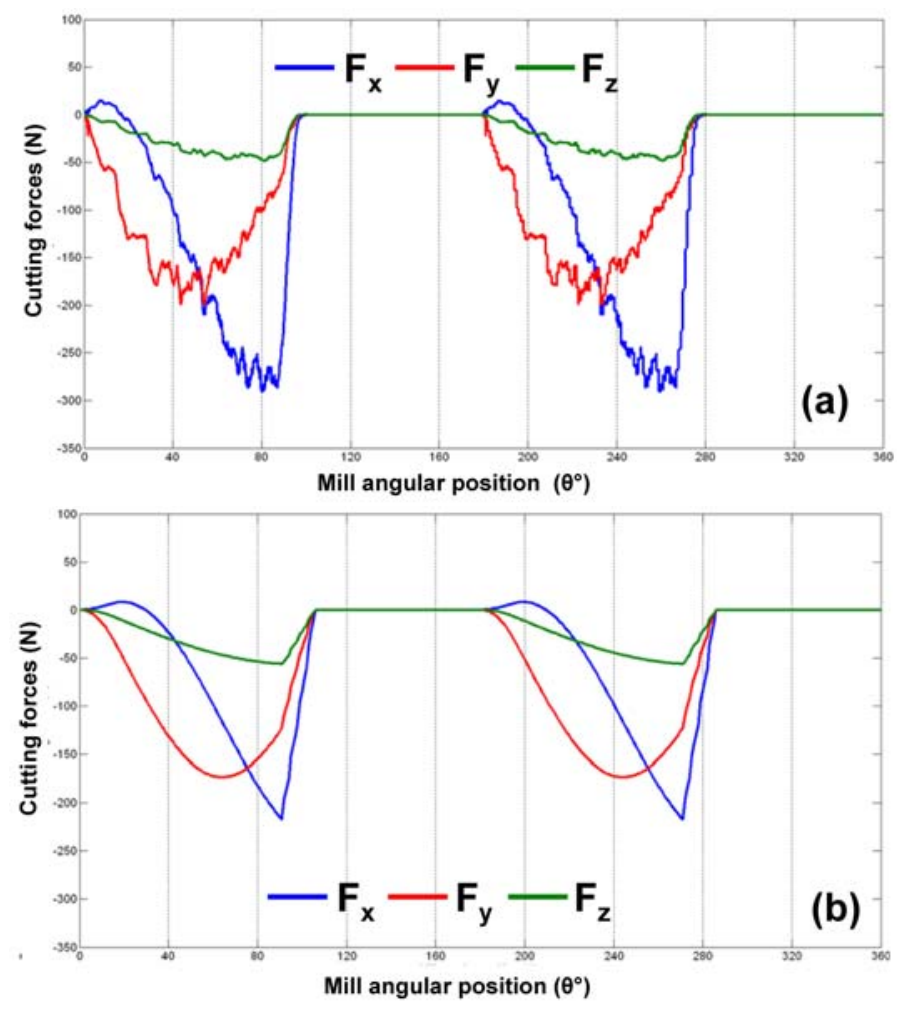

Fig.10. Comparison between FEM (a) and analytical (b) curve shapes of cutting forces in up milling for two tooth paths

Here, we lead on a discussion concerning only the curve shapes of cutting forces. And the following conclusions can be made:

- For the force orthogonal to the feed direction $F_{X}$, the same curve shape is observed for both models. A first peak appears and corresponds to the initial force projection at the 
tool entrance in material. Then a quasi-linear decrease is observed in the case of analytical model when for the FEM model the decrease seems to be more curved and to finish softly. This phenomenon is due to a better modelling of the chip ejection in the case of FEM modelling. This decrease finishes on a peak and is followed by a fast increase and then by a null value representing the period where no tooth is engaged in material.

- For the force in the feed direction $F_{Y}$, both curves present a parabolic curve shape. Nevertheless, on the analytical curves, a nickpoint is observed corresponding to the tool exit in the material. This phenomenon occurs less clearly on the FEM curve and a delay is observed (a gap equal to $10^{\circ}$ is measured). The chip seems to resist longer in FEM simulations than in the analytical model and seems to be retained in a direction close to $\mathrm{Y}$ axis. This assumption is also validated by the chip formation in the simulations, where the chip split up with difficulty from the vertical face of the rough surface (Figure 7).

- Concerning the axial force $F_{Z}$ along the tool axis, the cutting forces curves show the same curve shape: a parabolic increase interrupted by a peak and a rapid increase.

To conclude the cutting forces curves obtained with the FEM simulation present the same general evolution than the curves obtained analytically with the hypothesis of a tool not deformable and not flexible. The finite element simulations allow obtaining cutting forces curves coherent with the assumptions. In fact, the curve shapes represent properly an up milling operation with a rigid tool. Naturally the next step consists to compare the FEM cutting forces curves with those obtained from experiments.

\subsection{Experimental validation}


Then, we perform the academic test, described in section 3.1 on a machine-tool in order to compare the cutting forces curves obtained by finite element simulations and cutting forces measured experimentally. The experimental device used to obtain experimental curves is based on a $\operatorname{Kistler}^{\circledR}$ dynamometer using piezoelectric accelerometers technology.
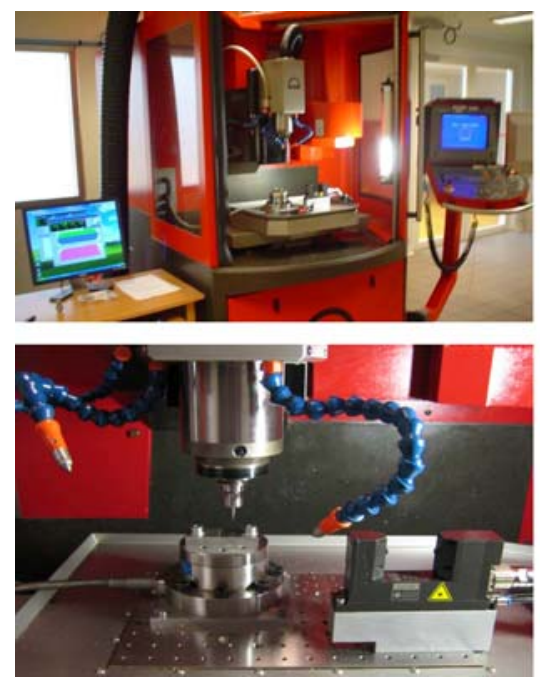

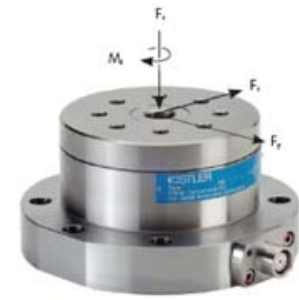

Kistler® dynamometer 9272

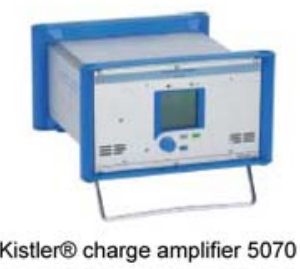

Fig.11. Experimental set up to measure the cutting forces in milling

The experiments were carried out on a 3 axes $\operatorname{Kern}^{\circledR}$ micro-milling machine, which was chosen for its high accuracy and rigidity. As we can see on Figure 11, the dynamometer is fixed on the machine's table, and then is connected to a computer through a charge amplifier and an input/output data acquisition card. Real-time data checking and force determination in milling are available through specific software providing data processing capabilities. For instance, the acquisition frequency can be compared to the dynamometer's limit in order to validate the test. Finally, the signals are checked through a spectral analysis to verify their stability and their relevance. All the test specimens are machined in the same material specimen and in the same geometry: $80 \mathrm{~mm}$ x $40 \mathrm{~mm}$ x $10 \mathrm{~mm}$. The milling experiments are carried out without lubrication. During the experimental investigations of milling, high speed milling and micro-milling, numerous cutting conditions were tested. The accuracy and repeatability of the experimental device was checked from milling tests but also calibration 
tests on a compression testing machine. In figure 12, we relate the experimental cutting forces of a conventionnal milling operation (i.e. with standard industrial cutting condition and low cutting speed). A very good description of curve shapes close to the rigid tool assumptions is obtained thanks to the fact that no perturbations due to dynamic effects and phenomena annex to cutting occured.

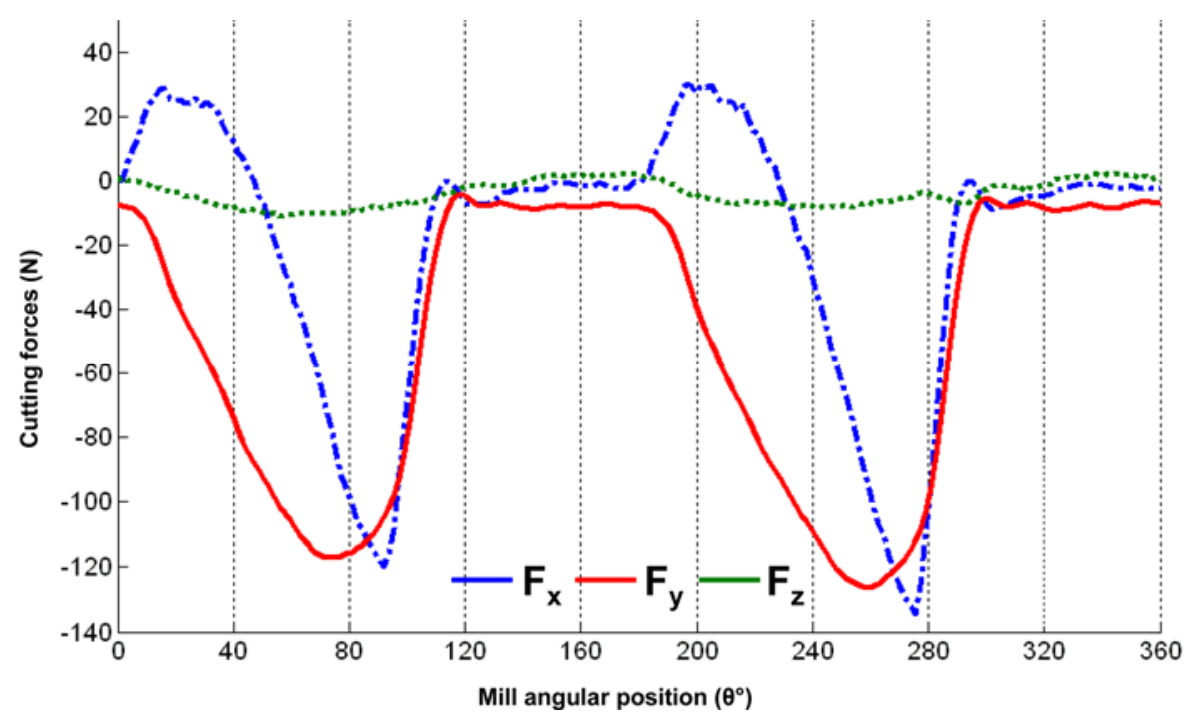

Fig.12. Experimental cutting forces curves for a conventionnal operation (70 m.min ${ }^{-1} \& 0.5$ mm.tooth ${ }^{-1}$ )

In order to confront the numerical model with experimental cutting forces curves, the academic tests previously mentioned with two teeth $6 \mathrm{~mm}$ diameter end mills was led in up milling configuration described in Table 3. The cutting conditions corresponding to the experiments are related in Table 2. The experimental cutting forces are related in Figure 13. Some remarks should be made at that step. On the experimental curves, we can see that the measure of $F_{X}$ and $F_{Z}$ cutting forces is little perturbated and the curve shapes differs from the considered ones for analytical modelling with rigid tool assumptions. In academic experiments, the feed rate was extreme for the considered tool. And this high value induced perturbations due to the apparition of new phenomena at the cutting interface. Due to this critical parameter, we can see on Figure 13 that the material removal is not very stable particularly when no tooth is in cutting position. 


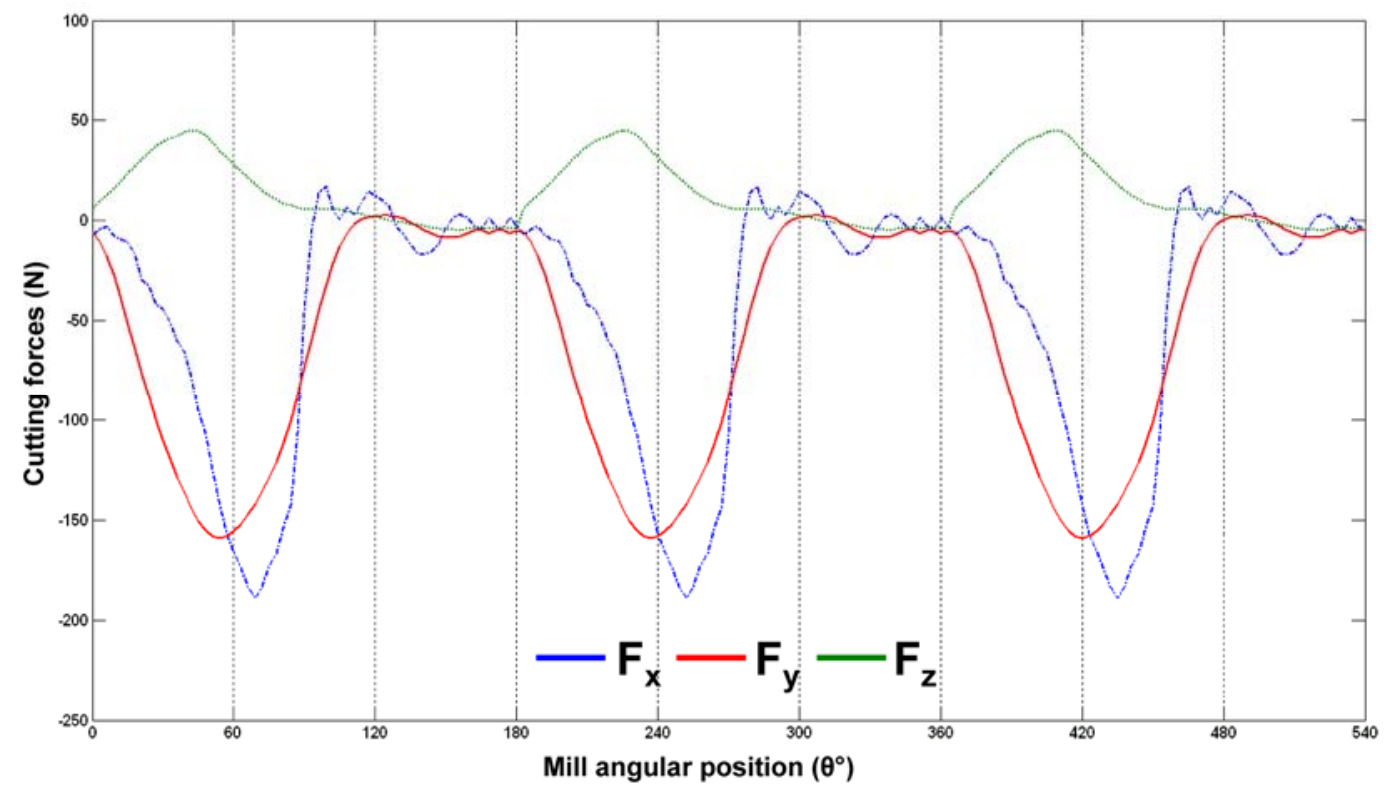

Fig.13. Experimental cutting forces curves for the academic test defined in Table 2.

That is why the $F_{X}$ cutting force is more perturbated by oscillations than the $F_{Y}$ cutting force. In fact in $\mathrm{X}$ direction, we have a discontinuity at the end of the tooth path when cutting is finished and the chip is removed. This abrupt change of the chip thickness at the end of the tooth path is traduced by a fast decrease of loads on the tool. This phenomenon has a specific frequency due to the tool rotation and induces vibrations on the tool axis. These vibrations create perturbations on the tool engagement in matter and small modifications on the $F_{X}$ curve shape.

In the same way, the $F_{Z}$ cutting force is more perturbed than the $F_{X}$ and the $F_{Y}$ cutting forces. One reason is that perturbations have more influence on $F_{Z}$ cutting force because in $Z$ direction, the cutting forces are smaller and more sensitive than in other directions $(\mathrm{X}, \mathrm{Y})$. Moreover, $F_{Z}$ cutting force is more difficult to analyse because of occurring of complex phenomena annex to cutting around the tool tip. These non cutting phenomena as cutting refusal and ploughing are not considered in analytical and finite element models. These mechanical effects around tool tip have a high influence in $\mathrm{Z}$ direction and tend to increase 
the $F_{Z}$ cutting force. These observations permit to justify also the perturbations observed on curve shapes of $F_{X}$ and $F_{Z}$ cutting forces.

In the same way, the reason of a positive experimental axial force $F_{Z}$ when the FEM and analytical models show a negative value can be explained. Indeed, $F_{Z}$ becomes positive with cutting refusal and ploughing phenomena increased by tool wear. After the academic operation, an observation shows that the end mill quickly changes its geometry in a bull-nose one. A ball-end mill and bull-nose end mill provide positive cutting force on Z-axis for a straight cut test as shown in previous work (Wang et al, 2002)(Fontaine et al., 2007)[20][21][22].With a measure proportionally more perturbed and some phenomena not taken into account, differences between the measured $F_{Z}$ cutting forces and the predicted ones are more significative. Nevertheless, the $F_{X}$ and $F_{Y}$ cutting forces are always considered as the main significant cutting forces in milling. These criteria are used classically to optimise the cutting conditions, to describe the dynamic behaviour of tool or workpiece and to evaluate the residual stress or the machined surface roughness.

Finally, for all cutting forces, the area between peaks presents some discrepancies mainly due to the effect of dynamic tool motion. Figure 14 describes for each cutting force curve the comparison between simulation and experiments. In spite of the differences and discrepancies due to the extreme cutting conditions of the tests, the curve shapes of the cutting forces curves are globally similar, even if a light temporal gap appears for the $F_{Y}$ force. 

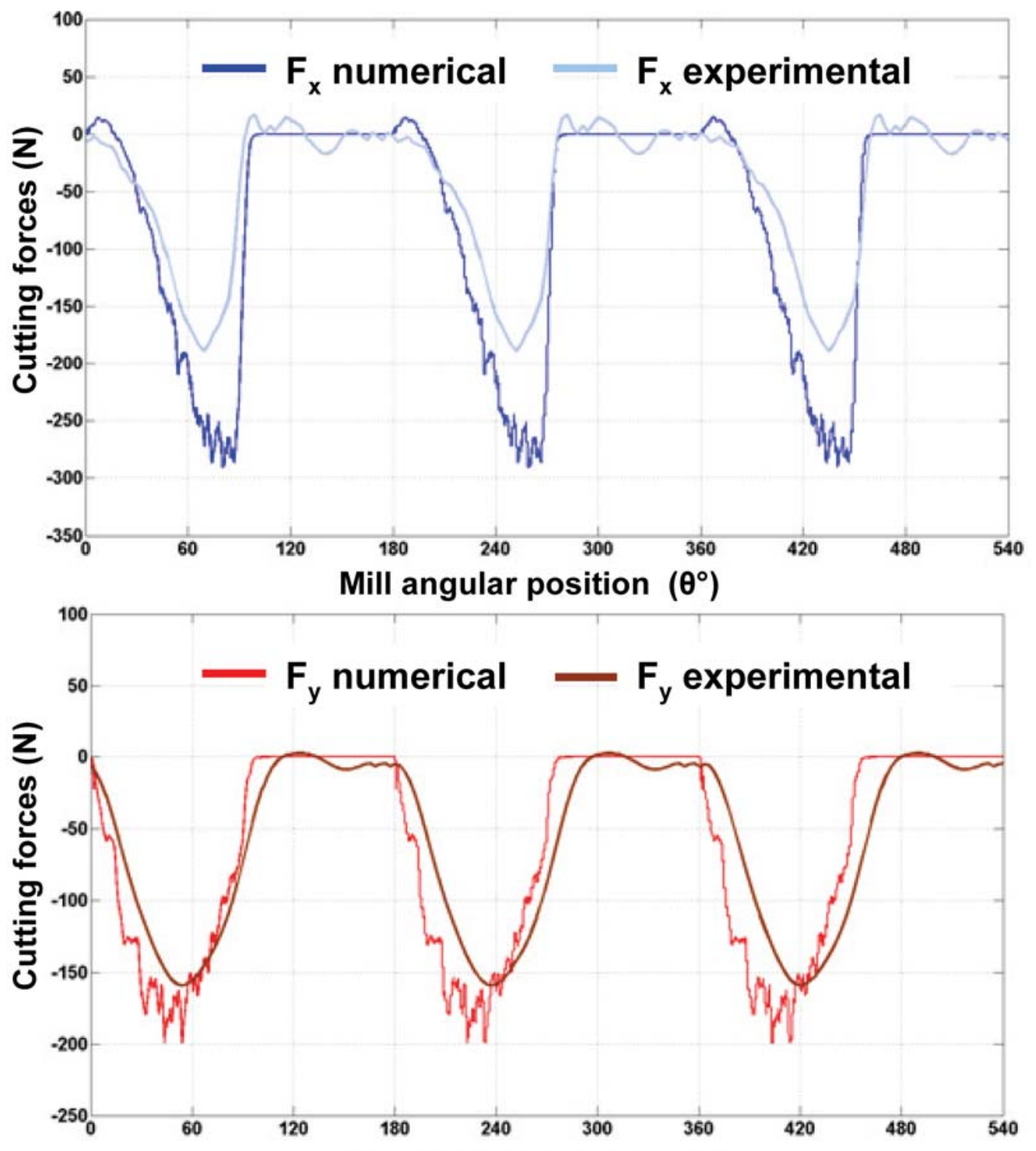

Mill angular position $\left(\theta^{\circ}\right)$

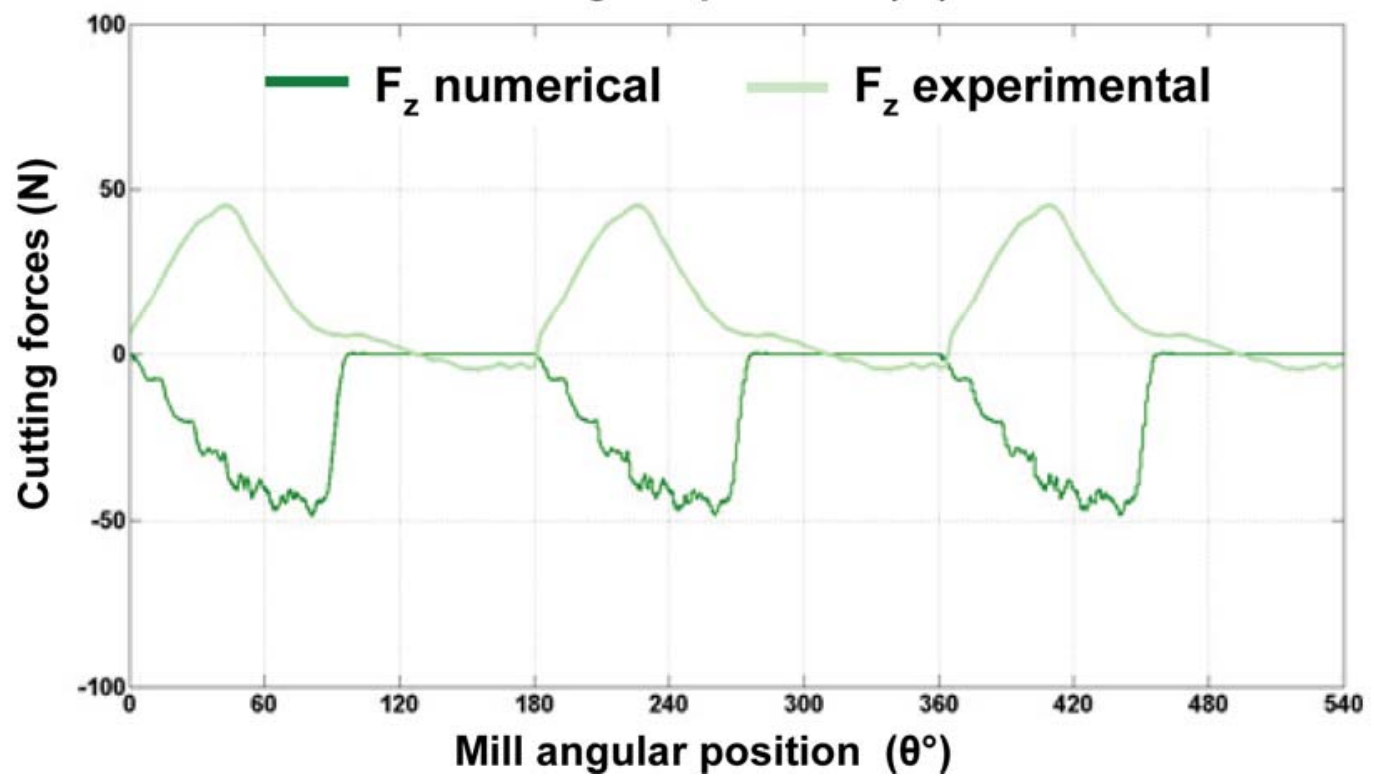

Fig.14. Comparison between the numerical and the experimental cutting forces for three tooth paths 
Concerning the cutting forces values, the following discrepancies can be observed:

- A positive discrepancy of $35 \%$ is observed on $F_{X}$ transverse force between the numerical and experimental curves.

- A positive discrepancy of $10 \%$ is observed on $F_{Y}$ feed force.

- For the vertical $F_{Z}$ force, experimental measurements are disturbed by the cutting conditions and the final comparisons are quite difficult. However, by considering the absolute value, the values are very similar and a discrepancy of less than $5 \%$ is observed.

In conclusion about this validation, the proposed numerical model permits to obtain accurately the cutting forces curves corresponding to the hypothesis of a rigid engagement. The cutting forces curves present the expected shapes for a shoulder milling operation in up and down milling configurations with an end mill. The values of the cutting forces are directly conditioned by the value of the failure criterion introduced in the numerical model. The choice of the criterion value allows obtaining acceptable values of cutting forces according to the simplifications introduced in this model. Indeed, the thermal softening of the material is not accounted in this FEM model. It is one of the main reasons why the results tend to surestimate the cutting forces values. It is important to note, that in milling process, the scale factor between the mill diameter and the usable feed rate limits the feasibility of these simulations. Indeed, higher the scale factor is, smaller the mesh size $a_{\text {elem }}$ is, and more critical the computational time becomes in an explicit scheme. The final aim of this study consists in using this type of numerical model as a tool to set up identification or optimisation procedures (Maurel et al., 2008); (Maurel-Pantel, 2009) [23,24]. 


\section{Conclusions}

FEM models of up and down shoulder milling built on basis of an academic test have been developed.This paper underlines rules and methodologies used to represent tool and workpiece meshes. Then, the different results focus on the cutting forces, the chip formation, stresses and strains contours. The numerical cutting forces curves present a coherent evolution with the curves obtained analytically. The proposed model is able to accurately describe the cutting forces curves for a shoulder milling operation according to the rigid tool assumption. This numerical model of milling constitutes a very important first original results in comparison with the published literature. Finally the experimental validations confirm the previous result. The FEM cutting forces curves, in the academic conditions, present coherent and predictive values in relation with the experimental cutting forces, even with simplifying assumptions. This 3D numerical model of milling constitutes a very important step in modelling of machining. It is an original contribution showing encouraging results in the field of numerical modelling of machining processes. Moreover, the developed model shows an interesting potential for the modelling of micro-milling operations.

Nevertheless, it seems interesting to improve the model and to validate the finite element simulations in an industrial case. An accurate tool geometry can be reconstructed and used but a lot of difficulties appear to define correctly the mesh of a complex tool CAD model. Nowadays, the most important limit is always the computation time. Until now, it is a limitation in performing industrial simulations. But some improvements will be continued in this field to propose new numerical modelling procedures in order to reach real industrial cutting conditions and more complex tool pathes. 


\section{Acknowledgements}

The CETIM fundation is greatly acknowledged for providing the $\mathrm{PhD}$ grant support to $\mathrm{Dr}$ Maurel-Pantel. We would also like to thank Dr. G. Michel for his help in measuring the cutting forces on the micro milling machine KERN.

\section{References}

[1] S. Lo, An analysis of cutting under different rake angles using the finite element method, Journal of Materials Processing Technology 105 (2000) 143-151.

[2] Y. Yen, A. Jain, T.A. Altan, Finite element analysis of orthogonal machining using different tool edge geometries, Journal of Materials Processing Technology 146 (2004) 7281.

[3] A. Mamalis, M. Horvath, A. Branis, D. Manolakos, Finite element simulation of chip formation in orthogonal metal cutting, Journal of Materials Processing Technology 110 (2001) 19-27.

[4] M. Baker, Finite element investigation of the flow stress dependence of chip formation, Journal of Materials Processing Technology 167 (1) (2004) 1-13.

[5] D. Umbrello, L. Filice, S. Rizzuti, F. Micari, On the evaluation of the global heat transfer coefficient in cutting, International Journal of Machine Tools \& Manufacture 47 (2007) $1738-1743$. 
[6] D. Umbrello, L. Filice, S. Rizzuti, F. Micari, L. Settineri, On the effectiveness of finite element simulation of orthogonal cutting with particular reference to temperature prediction, Journal of Materials Processing Technology, 189 (2007) 284-291.

[7] J. Outeiro, J. Pina, I. Jawahir, Experimental and numerical analysis of residual stresses produced in three dimensional machining processes, in Proceedings of the CIRP Conference on modelling of machining operations (Sicily, 2007).

[8] M. Fontaine, A. Devillez, D. Dudzinski, Parametric geometry for modelling of milling operations, International Journal of Machining and Machinability of Materials 2 (2007) 186205.

[9] T. Ozel, T. Altan, Process simulation using finite element method prediction of cutting forces, tool stresses and temperatures in high speed flat end milling, International Journal of Machine Tools \& Manufacture 40 (2000) 713-738.

[10] E. Uhlmann, A. Mattes, R. Zettier, V.D. Graf, M. Schulenburg, Investigations on the adjustement of the modeling section in 2D simulation of milling processes, in Proceedings of the CIRP Conference on modelling of machining operations, (Sicily, 2007).

[11] B. Denkena, L. de Leon Garcia, J. Kohler, FEM simulation of high performance milling, in Proceedings of the CIRP Conference on modelling of machining operations, (Sicily, 2007). 
[12] I. Korkut, M. Kasap, I. Ciftci, U. Seker, Determination of optimum cutting parameters during machining of AISI 304 austenetic stainless steel, Materials and Design 25 (2004) 303305.

[13] Z. Tekiner, S. Yesilyurt, Investigation of the cutting parameters depending on process sound during turning of AISI 304 austenitic stainless steel, Materials and Design 25 (2004) $507-513$.

[14] D. O’Sullivan, M. Cotterell, Machinability of austenitic stainless steel SS303, Journal of Materials Processing Technology 124 (2002) 153-159

[15] G.R. Johnson, J.R. Cook, 1983, Constitutive model and data for metals subjected to large strains, high strain rates, and high temperatures, in Proceedings of 7th Symposium On Ballistics, (Netherlands, 1983)

[16] A. Moufki, A. Devillez, D. Dudzinski, A. Molinari, Thermomechanical modelling of oblique cutting and experimental validation, International Journal of Machine Tools \& Manufacture 44 (9) (2004) 971-989.

[17] M. Movahhedy, Y. Altintas et M. Gadala, Numerical analysis of metal cutting with chamfered and blunt tools, Journal of Manufacturing Science and Engineering, (124) (2002) $178-188$. 
[18] Y. Yen, A. Jain et T. Altan, A finite element analysis of orthogonal machining using different tool edge geometries, Journal of Materials Processing Technology, (146) (2004) 7281.

[19] M. Fontaine, A. Devillez, A. Moufki, D. Dudzinski, Predicitve force model for ball end milling and experimental validation with a wavelike form machining test, International Journal of Machine Tools and Manufacture 46 (2006) 367-380.

[20] J.-J.J. Wang, C.M. Zheng, Identification of shearing and ploughing constants from average forces in ball-end milling, Int. J. Mach. Tools Manuf., 42 (6) (2002) 695-705.

[21] M. Fontaine, A. Moufki, A. Devillez, D. Dudzinski, Modelling of cutting forces in ballend milling with tool-surface inclination. Part II: Influence of cutting conditions, run-out, ploughing and inclination angle, Journal of Materials Processing Technology, (189) (2007) 85-96.

[22] M. Fontaine, A. Devillez, D. Dudzinski, Parametric geometry for modelling of milling operations, International Journal of Machining and Machinability of Materials, (2) (2007) 186-205.

[23] A. Maurel, M. Fontaine, S. Thibaud, G. Michel, J.C. Gelin, Inverse Method for Identification of Material Parameters Directly from Milling Experiments, International Journal of Material Forming 1 (2008) 1435-1438. 
[24] A. Maurel-Pantel, Experiments and finite element modeling of milling process: parametric identification of behavior laws, Ph.D. Thesis, Applied Mechanical Departement of FEMTO-ST Institute, University of Franche Comté (France), 2009. 